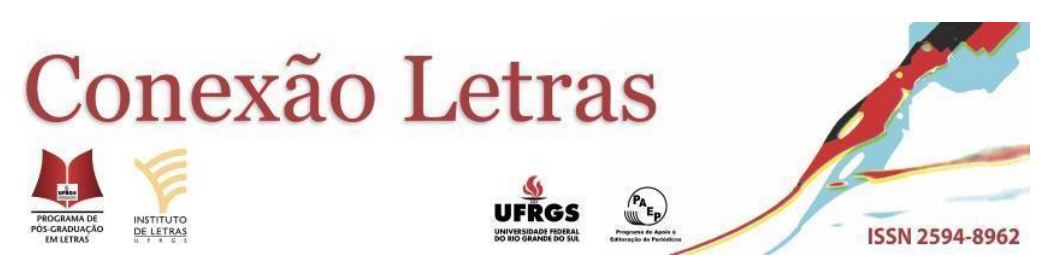

\title{
A ARGUMENTAÇÃO COMO PROCESSO DE SIGNIFICAÇÃO
}

\author{
THE ARGUMENTATION AS A MEANING PROCESS
}

Neuza Zattar ${ }^{1}$

Resumo: Este artigo analisa na perspectiva da Semântica da Enunciação, de Eduardo Guimarães, como a argumentação, enquanto sustentação do que se diz, significa em cenas enunciativas recortadas de textos eletrônicos que abordam relações políticas entre o presidente da República e as instituições do país, articulados ao agenciamento das figuras enunciativas e às paráfrases, por considerar que a relação de sustentação entre um $e u$ e um $t u$ é uma relação de linguagem, uma relação enunciativa.

Palavras-chave: Semântica da Enunciação. Argumentação. Figuras Enunciativas. Argumentatividade.

Abstract: This article analyzes from perspective of the Semantics of Enunciation, by Eduardo Guimarães, as the argumentation, as supporting of what is said, means in enuncative scenes cut from eletronic texts that address political relations between the president of the Republic and the country's institutions, articulated to the agency of enunciative figures and paraphrases, considering that the support relationship between a self and a you is a language relationship, an enunciative relationship.

Keywords: Enunciation Semantics. Argumentation. Enunciative Figures. Argumentativeness.

\section{Introdução}

A discussão sobre a Retórica é anterior a Aristóteles, mas é a Retórica deste filósofo, instituída na Antiguidade, que será apreendida nos séculos seguintes até a atualidade, cuja premissa se pauta na arte de falar em público de modo persuasivo. Aristóteles, ao enfatizar a oralidade, tem como alvo o convencimento e a persuasão por meio de argumentos fundamentados na razão (logos) ou na emoção (phatos), e defende a argumentação retórica como a que só tem validade se alcançar a adesão do auditório.

$\mathrm{Na}$ segunda metade do século XX, uma Nova Retórica foi criada e vem sendo discutida nas instituições de ensino superior no Brasil, trata-se da obra Tratado da Argumentação: a nova retórica, de Perelman e Olbrechts-Tyteca, publicada em 1958, do século passado. A argumentação definida por esses autores como "a prática da argumentação se dá pelo contato entre o orador e seu interlocutor, visando obter a adesão daqueles a quem se

\footnotetext{
${ }^{1}$ Licenciada em Letras pela Faculdade Dom Aquino de Filosofia e Letras (Campo Grande-MS), concluiu Mestrado (2000) e Doutorado (2007) em Linguística pela Unicamp. Atua como professora permanente no Programa de Pós-Graduação em Linguística da Unemat/Campus de Cáceres e participa do Projeto de Pesquisa "Significar Mato Grosso", que resultou na produção do texto "Jacobina, Facão e Ressaca: referenciais históricos de atividades econômicas de Mato Grosso no século XIX", que se encontra no pelo, e desenvolve trabalhos na perspectiva da Semântica da Enunciação. Tem publicação de livros e artigos. Atualmente desenvolve o Projeto Reedição do livro Um trecho do oeste brasileiro (193), de Gabriel Pinto de Arruda, aprovado pela SECEL/MT, com aporte financeiro da Lei Aldir Blanc/2020.
} 
dirige (o auditório), sem apresentar, no entanto, uma verdade única” (p. 21), encontra-se referenciada na publicação brasileira de $1996^{2}$.

Desse modo, para os autores, a defesa da argumentação não está a serviço de demonstração por meio de provas ou da verdade para se chegar à conclusão, mas da adesão consensual do auditório à tese apresentada.

Também na segunda metade do século XX, Ducrot e Anscombre (1983), ao desenvolverem a Teoria da Argumentação na Língua, afirmam que a argumentação está inscrita na língua, nas frases mesmas, ou seja, "a argumentação está inscrita estruturalmente na língua, especificamente no léxico.” (ZOPPI-FONTANA, 2006, p. 195).

Não é nosso interesse neste trabalho desenvolver um estudo teórico sobre a argumentação, mas de situá-la para se pensar como a argumentação tratada por Aristóteles ainda se mantém como ferramenta de persuasão e convencimento do interlocutor, e tomo como exemplo bem atual a Cartilha do Exame Nacional do Ensino Médio (Enem), a qual estabelece como critério, para a prova de redação, a defesa de uma opinião sobre o tema proposto pelo participante, sustentada "por argumentos consistentes, estruturados com coerência e coesão, formando uma unidade textual"'3. Para os organizadores do Enem, a argumentação significa a defesa da tese com o objetivo de convencer o leitor. Nessa proposta, fica evidente a articulação da argumentação com elementos da retórica e da linguística textual, que se fundem para dar ao texto da redação a conformação exigida pelo Enem.

A argumentação, nessa perspectiva, além de ser empregada na redação do Enem e por instituições escolares que preparam alunos para os exames de acesso às IES, está presente em várias relações de linguagem cotidianas e profissionais, nos discursos políticos, econômicos e institucionais e, principalmente na mídia e nas redes sociais, onde vicejam argumentos a favor ou contra o que se posta sobre pessoas do meio político, artístico e intelectual.

Diferentemente da posição do MEC que orienta a formulação da redação do Enem, sustentada pela retórica aristotélica que defende a argumentação sob o ponto de vista da persuasão e do convencimento; da visão de Perelman e Olbrechts-Tyteca, para os quais a argumentação é uma relação consensual entre o discurso do orador e o auditório; e da posição de Ducrot e Anscombre (1988), que defendem que a argumentação está inscrita na língua; adotaremos neste trabalho a posição de Guimarães (2018, p. 95), que define a argumentação como "o elemento do processo de significação, produzida pelo acontecimento da enunciação."

\footnotetext{
${ }^{2}$ A definição de argumentação pelos autores Perelman e Olbrechts-Tyteca se reporta à tradução brasileira de 1996.

${ }^{3}$ Cf. Redação do ENEM 2018. Cartilha do Participante. Apresentação. Brasília/DF, 2018, p. 7.
} 
Ou seja, a significação da argumentação se dá no funcionamento da língua no acontecimento da linguagem pelo agenciamento das figuras enunciativas.

Nessa linha, propomos analisar na perspectiva da Semântica da Enunciação como a argumentação do que se diz significa em cenas enunciativas recortadas de textos eletrônicos que abordam relações políticas entre o presidente da República e as instituições do país, articulados ao agenciamento das figuras enunciativas e às paráfrases, por considerar que a relação de sustentação entre um eu e um tu é uma relação de linguagem, uma relação enunciativa.

$\mathrm{O}$ acontecimento de enunciação, pelo agenciamento do falante a dizer, estabelece as cenas enunciativas divididas politicamente por lugares de enunciação, que correspondem, segundo Guimarães (2018, p. 50), ao(s):

\footnotetext{
a) Locutor - agenciado pelas sistematicidades linguísticas, institui aquele que diz;

b) Alocutores - agenciados pelas condições históricas e sociais do falante, instituem os lugares sociais do dizer;

c) Enunciador - um lugar de dizer que não é um lugar de enunciação- $X$, ou seja, o enunciador é um lugar- $x$ "que se relaciona com o que se diz no acontecimento, por modos distintos, significando relações diferentes entre o lugar de dizer e o que se diz.
}

De modo que a relação da alocução se constitui de Locutor (L), que tem como seu correlato do dizer um Locutário ( $\mathrm{Lt}$ ), e de Alocutor (al) que se apresenta tendo como seu correlato o Alocutário (at).

Antes de passarmos à análise dos recortes, vamos apresentar os conceitos de enunciação e do funcionamento do espaço da enunciação e da cena enunciativa, os quais consideramos importantes para se compreender como a argumentação se constitui no processo de significação da linguagem no acontecimento da enunciação.

\section{A enunciação}

A enunciação (o que se diz) é tratada por Guimarães (2018) como o acontecimento de produção de enunciados e sentidos em um espaço de enunciação específico, no qual se dá o funcionamento de línguas e falantes. Nessa perspectiva, a língua é tomada como histórica e se apresenta pela prática humana e por relações que fundamentam o funcionamento dessa prática com vistas a produzir significações, ou seja, a linguagem. $O$ falante, também indispensável na relação com a(s) língua(s), não é um figura empírica ou psicológica, mas uma figura linguística constituída pelas línguas do espaço de enunciação. Assim, é no espaço de 


\section{ZATTAR, Neuza.}

enunciação que as línguas funcionam na sua relação com os falantes, distribuídas desigualmente visto que o espaço de enunciação é um espaço político de funcionamento de línguas, do mesmo modo que o agenciamento dos falantes pelas línguas é também político. Essa relação de línguas com seus falantes, no entanto, tende a se complexizar com a instituição de outras línguas e de outros falantes (por exemplo, línguas e falantes estrangeiros) no espaço de enunciação que se modifica conforme as relações políticas envolvidas. (GUIMARÃES, 2018).

O acontecimento, por exemplo, críticas do presidente da República a instituições e/ou poderes constituídos do país em lugares públicos e institucionais, tem uma especificidade por constituir uma diferença em relação à posição política de um chefe da nação, e é essa diferença que constitui a especificidade do acontecimento que Guimarães (2018) chama de temporalidade de sentidos: um passado, um presente e um futuro. $\mathrm{O}$ sentido do dizer que se faz presente é tomado pelo sentido de enunciações já ditas em outros tempos e lugares e o futuro são os sentidos que esse dizer projeta e se presentifica em outras enunciações.

O acontecimento da enunciação produz sentidos na cena enunciativa constituída pelo agenciamento do falante em figuras da enunciação. "O acontecimento, pelo agenciamento do falante a dizer, estabelece as cenas enunciativas por uma divisão dos lugares de enunciação.” (GUIMARÃES, 2018, p. 50). Ou seja, é na cena enunciativa, na alocução propriamente dita, que ocorrem os sentidos das relações de linguagem determinadas pelas condições históricas e sociais dos falantes.

\section{Análise}

Partindo da premissa de que a argumentação funciona como sustentação ao que se enuncia, vamos às análises dos recortes:

R1 [A1] A Rede Globo divulgou na manhã desta quarta-feira, 30, uma nova nota defendendo o trabalho de sua equipe de jornalismo, depois de ser novamente criticada pelo presidente Jair Bolsonaro, em viagem no exterior. [A2] No texto a empresa afirmou ter independência para informar fatos, "mesmo aqueles que possam irritar as autoridades" ${ }^{4}$. (Grifo nosso).

\footnotetext{
${ }^{4}$ Publicado em 30/10/2019. Disponível em:

https://istoe.com.br/rede-globo-reage-a-bolsonaro-e-diz-que-e-independente-para-informar/. Acesso em: out. 2018. 
A cena enunciativa do R1, pela própria natureza política de que é constituída, expõe um confronto entre a Rede Globo e o presidente da República, e traz como memorável o litígio desencadeado por meio de sistemáticos ataques do presidente contra os jornalistas da Globo, gerados pela insatisfação da cobertura que fazem de seu governo.

Tratando-se da figura maior do poder de Estado e da Rede Globo e pelo que essa representação do Executivo e a Globo significam, a matéria ganha materialidade e importância para a revista IstoÉ por diversas razões: a) pelo que esses lugares de dizer representam e significam social e politicamente para o país; b) pela reação dos leitores que convivem num país polarizado politicamente; e c) pelos comentários pró ou contra de usuários nas redes sociais sobre assuntos que envolvem a Rede Globo e o presidente. E são essas e outras interpretações que tornam o texto significativo, e que aqui será tomado como unidade de produção de sentidos pela relação de transversalidade com outros enunciados.

Vamos considerar agora o funcionamento das figuras enunciativas na cena enunciativa do R1: pelo agenciamento das sistematicidades linguísticas, temos um falante que é instituído em Locutor (L) que diz algo a alguém, o Locutário (Lt), ou seja, o Locutor ( $\mathrm{L}=$ Rede Globo) representado por um eu que diz em nota para um $t u(\mathrm{Lt}=$ presidente Bolsonaro). Pelo agenciamento das condições sociais e históricas do falante, temos um alocutor-x (lugar social de quem diz = revista $I s t o E ́$ ) que rediz a um alocutário- $x$ (lugar social para quem se diz $=$ leitor virtual) sobre a nota de defesa da Globo em resposta às críticas do presidente Bolsonaro. Tratando-se de um texto (R1) constituído de discurso relatado, o redizer da revista IstoÉ produz um sentido específico pelo modo como a enunciação do recorte integra os demais enunciados da matéria publicada.

É interessante observar o funcionamento da 'nota de defesa da Globo' que significa no recorte "aquilo sobre a qual se enuncia, que não é um lugar de enunciação nem um lugar para o qual se enuncia" (GUIMARÃES, 2018, p. 97), ou seja, esse lugar não se constitui em figura enunciativa e, portanto, não é agenciado no espaço de enunciação.

Tomamos para análise a primeira ocorrência em [A1] do recorte 1.

[A1] [A] A Rede Globo divulgou na manhã desta quarta-feira, 30, uma nova nota defendendo o trabalho de sua equipe de jornalismo, [B] depois de ser novamente criticada pelo presidente Jair Bolsonaro, em viagem no exterior. ${ }^{5}$ (Grifo nosso).

\footnotetext{
${ }^{5}$ Publicado em 30/10/2019. Disponível em: https://istoe.com.br/rede-globo-reage-a-bolsonaro-e-diz-que-e-independente-para-informar/. Acesso em: out. 2018. 
Nessa ocorrência, a relação $\mathrm{A}$ depois de $\mathrm{B}$ significa a atribuição de sentidos à argumentação pelo agenciamento do alocutário-x, que, do lugar social da revista IstoÉ sustenta a argumentação da defesa da Rede Globo em nota publicada na revista IstoÉ, no sentido de legítima defesa.

Vejamos a representação dessa relação:

Argumento A - A Rede Globo divulgou na manhã desta quarta-feira, 30, uma nova nota defendendo o trabalho de sua equipe de jornalismo.

Argumento B - depois de ser novamente criticada pelo presidente Jair Bolsonaro, em viagem no exterior.

Conclusão: nota de defesa da Rede Globo à crítica do presidente

Vimos que na ocorrência em [A1], a argumentação se dá pela relação entre os lugares sociais dos falantes, ou seja, entre o lugar que enuncia (al-x) e o lugar para quem enuncia (at-x) e, nessa ocorrência, o lugar social que enuncia, representado pela revista IstoÉ, sustenta o que se diz pelo lugar de seu agenciamento na enunciação como aquele que relaciona um argumento e uma conclusão (GUIMARÃES, 2018), ou seja, a conclusão da defesa. Trata-se aqui de uma relação de enunciação e não de uma relação de convencimento ou de demonstração da verdade comum na argumentação de origem aristotélica.

$\mathrm{Na}$ ocorrência em [A1], observamos que o articulador depois de liga dois acontecimentos de enunciação distintos que constituem a sua própria temporalidade de sentidos: as enunciações realizadas que já significaram, continuam a significar no presente do dizer, projetando outros desdobramentos de sentido. Ou seja, há um antes e um depois que fazem significar a temporalidade de sentidos dos acontecimentos que integram a ocorrência em [A1].

As expressões "nova" em "uma nova nota" da Rede Globo e "novamente" em "novamente criticada pelo presidente" significam que as relações entre as duas instituições não são inéditas, ao contrário, se repetem e se arrastam pela mídia, dadas as condições histórico-sociais dos falantes em cada um dos acontecimentos nos quais são agenciados a dizer.

Ainda na ocorrência [A1], temos o numeral “30" que reescritura por condensação "na manhã desta quarta-feira", trata-se aqui de um procedimento que ao redizer o mesmo faz significar de modo diferente.

Passamos à análise da segunda sequência do R1: 
[A2] No texto a empresa afirmou ter independência para informar fatos, "mesmo aqueles que possam irritar as autoridades".

Que pode ser parafraseada por:

[A2'] (A) Na nota a emissora diz que é independente para informar fatos, (B) até mesmo aqueles que possam irritar as autoridades.

Na paráfrase em [A2'], o elemento contíguo até mesmo é externo a [A2], o qual ao se articular com esse elemento produz o sentido de uma "afirmação" que se enuncia no acontecimento em [R1]. Na relação entre a enunciação que "comenta" [até mesmo os que irritam as autoridades] e a enunciação "comentada" [Na nota a emissora diz que é independente para informar fatos] em [A2'] ocorre a operação de contiguidade chamada relação de incidência, que, para Guimarães (2009, p. 51), significa "a relação entre um elemento de uma natureza e outro de outra natureza, de modo a formar um novo elemento do tipo do segundo".

É preciso observar que não é o alocutor-revista IstoÉ que julga a relação de litígio entre as partes, mas o enunciador-coletivo que, aludido pelo alocutor, se coloca como um lugar $X$ que se relaciona com o que diz no acontecimento. Ou seja, trata-se de um lugar de dizer que se relaciona com o modo 'como se diz o que se diz' e, ainda, por uma relação com o que se diz. (GUIMARÃES, 2018).

Veremos, agora, o procedimento de reescrituração em [A2]. Nesta ocorrência, a expressão "Rede Globo" reescritura por substituição "a empresa", e o enunciado "mesmo aqueles que possam irritar as autoridades" é reescriturado por condensação pela expressão "fatos". Ainda, as expressões "a empresa" em [A2] reescritura por sinonímia "a emissora" em [A2'] e da mesma forma a reescrituração de "No texto" [A2] por "Na nota" em [A2']. Estes procedimentos que redizem o dito são modos como os enunciados que integram o texto do (R1) significam.

Passamos à análise do recorte 2.

(R2) [B1] A última reunião entre Jair Bolsonaro e Luiz Henrique Mandetta, ainda como ministro da Saúde, teve um diálogo marcante, segundo a jornalista Denise Rothenburg, do Correio Braziliense.

[A] "Você será responsabilizado pelas consequências, pelas mortes", disse Mandetta a Bolsonaro. [B] “Eu, não, os governadores é que vão!", respondeu Bolsonaro, aos gritos, de acordo com ela. Mandetta não respondeu mais e deixou o presidente falando sozinho, completa a nota da colunista. [B2] Os dois discordavam sobre as regras do isolamento social, com Bolsonaro querendo encerrar a quarentena e 
Mandetta seguindo as orientações da OMS, que vê o isolamento como única medida capaz de combater a contaminação do vírus. ${ }^{6}$ (Grifo nosso).

O (R2) é um texto integralizado de vários enunciados ocorridos em temporalidades distintas por uma relação transversal "entre elementos diversos e a unidade à qual se reportam." (GUIMARÃES, 2011, p. 57). O texto, formulado do lugar social do site BRASIL 247, argumenta sobre a discordância política entre as autoridades presidente da República e ministro da Saúde, à época, e é textualizado pela Locutora-jornalista na enunciação do Correio Brasiliense, que significa no presente da matéria site BRASIL 247.

Nessa linha, na enunciação do R2, temos o falante agenciado e dividido politicamente nas seguintes figuras enunciativas:

a) o Locutor ( $\mathrm{L}=$ jornalista do Correio Braziliense), representado por um eu que diz algo para um $t u$, o Locutário $(\mathrm{Lt})$, representado pelo leitor, num acontecimento anterior à matéria do site Brasil 247;

b) o alocutor (al-x), representado pelo site BRASIL 247, e o alocutário (at-x), o leitor-virtual, são agenciados na cena enunciativa do R2. O alocutor-Site BRASIL 247, ao incorporar a enunciação da matéria do Correio Brasiliense, relata a discussão entre os interlocutores ministro Mandetta e presidente Bolsonaro, provocada pela discordância a respeito dos procedimentos recomendados pela OMS para combater o vírus covid 19.

Nesta análise vamos nos deter na alocução da ocorrência em [B1].

[A] "Você será responsabilizado pelas consequências, pelas mortes", disse Mandetta a Bolsonaro. [B] “Eu, não, os governadores é que vão!”, respondeu Bolsonaro, aos gritos, de acordo com ela. ${ }^{7}$ (Grifo nosso)

Nessa alocução, a sustentação do que se enuncia se dá pelo agenciamento do site BRASIL 242 em alocutor- $x$, que, do seu lugar social, significa uma relação dos lugares sociais com as condições históricas do acontecimento enunciativo. Assim, verificamos que a relação entre os argumentos A e B tem como conclusão a discordância entre Mandetta e Bolsonaro, dado o agenciamento do falante a enunciar nesse acontecimento.

Vejamos a representação dessa relação argumentativa:

Argumento A - "Você será responsabilizado pelas consequências, pelas mortes".

\footnotetext{
6 Site BRASIL $247 . \quad$ Disponível em: https://www.brasil247.com/poder/bolsonaro-disse-a-mandetta-que-mortes-vao-cair-nas-costas-dos-governadores-nao -dele. Acesso em: abr. 2020.

7 Site $\quad$ BRASIL $247 . \quad$ Disponível em: https://www.brasil247.com/poder/bolsonaro-disse-a-mandetta-que-mortes-vao-cair-nas-costas-dos-governadores-nao -dele. Acesso em: abr. 2020.
} 
Argumento B - "Eu, não, os governadores é que vão!"

Conclusão: discordância entre Mandetta e Bolsonaro sobre as regras de isolamento social.

É interessante observar que a discordância entre os argumentos $\mathrm{A}$ e $\mathrm{B}$, que é próprio do político no sentido que lhe dá Guimarães, altera a relação política entre as figuras enunciativas, mas mantém os lugares sociais de cada uma nesse acontecimento de enunciação. A discordância mostra o litígio político entre os interlocutores provocado por diferentes pontos de vista em relação ao modo de operar o isolamento social no combate à pandemia de Covid 19 no país.

Essa relação de discordância entre os interlocutores significa o político que se caracteriza, conforme Guimarães (2018, p. 50), "pela oposição entre a afirmação da igualdade em conflito com uma divisão desigual do real produzida enunciativamente pelas instituições que o organizam: organizam os lugares sociais e suas relações, identificando-os (atribuindo-lhes sentido), e recortam o mundo das coisas, significando-as."

Vamos agora tratar da figura do enunciador. Diferente de outras figuras enunciativas, o enunciador não projeta um tu e é definido como "um modo de o eu se apresentar na sua relação com o que se diz de um lugar individual, universal, coletivo e genérico." (GUIMARÃES, 2018, p. 63). Ou seja, o enunciador é a figura enunciativa que não diz diretamente ao representar o que diz o "eu" na sua relação com o dizer de outros lugares. (Idem).

No texto (R2), o alocutor apresenta dois enunciadores, incluindo o dizer de cada um em acontecimento já realizado e, por essa especificidade, temos uma alocução constituída de figuras enunciativas representadas por Mandetta e Bolsonaro ocorrida em outro acontecimento e que será representada da seguinte forma:

Locutor (eu)

Locutário (tu)

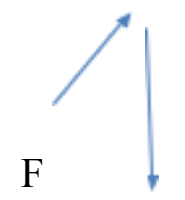

E (Univ.) "Você será responsabilizado pelas [...], pelas mortes".

Alocutor1-ministro da Saúde at-presidente da República

e

Locutor (eu) 


\section{ZATTAR, Neuza.}

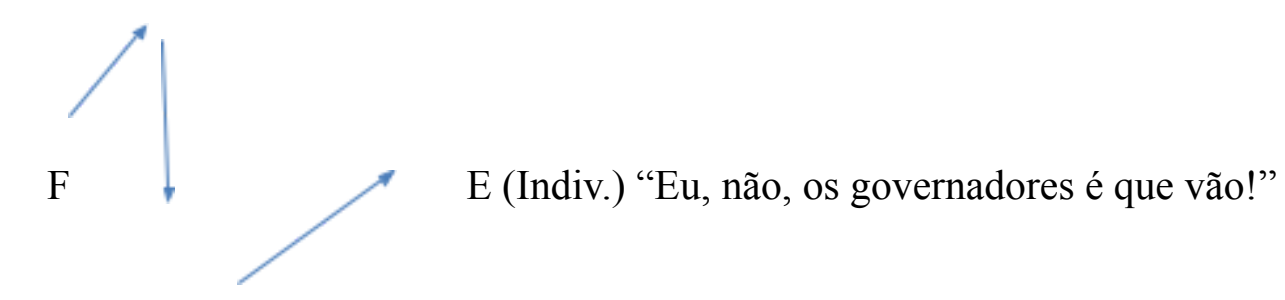

Alocutor2-presidente da República at-ministro da Saúde

Conforme a representação, podemos dizer que essa cena enunciativa se constitui pela movência dos lugares enunciativos. Ao enunciar "Você será responsabilizado pelas consequências, pelas mortes", o al-ministro da Saúde é aludido pelo enunciador-universal que diz do lugar da ciência, que conhece as orientações da OMS. Por outro lado, ao enunciar "Eu, não, os governadores é que vão!", o al-presidente da República é aludido por um enunciador-individual, que diz de um ponto de vista pessoal "Eu, não", transferindo a responsabilidade da flexibilização das medidas da OMS aos governadores, como mostra o enunciado "os governadores é que vão."

Passamos a analisar os procedimentos de sentido que semantizam o texto do R2:

1) de articulação:

Nos enunciados "A última reunião entre Jair Bolsonaro e Luiz Henrique Mandetta" e "Mandetta não respondeu mais e deixou o presidente falando sozinho", temos dois modos diferentes de articulação por coordenação. No primeiro, a coordenação articula dois elementos da mesma natureza (a mesma função sintática) e, neste caso, “o acontecimento especifica uma operação pela qual o Locutor relaciona elementos do enunciado" (GUIMARÃES, 2009, p. 51); e no segundo, a coordenação articula dois enunciados encadeando situações distintas. Essas articulações somam sentidos para a conclusão dos argumentos.

2) de reescrituração:

Temos:

a) reescrituração apositiva de nomes próprios por expressões linguísticas. Teríamos "Luiz Henrique Mandetta" reescriturado por aposição por "ministro da Saúde" e "Denise Rothenburg” por “a jornalista” e vice-versa;

b) reescrituração por definição de "isolamento" por "única medida capaz de combater a contaminação do vírus";

c) reescrituração por condensação dos nomes próprios "Mandetta e Bolsonaro" por "Os dois"; 
d) reescrituração por condensação de "um diálogo marcante" por "Você será responsabilizado pelas [...], pelas mortes" e "Eu, não, os governadores é que vão!"

Em (a) temos uma relação entre nomes próprios e expressões apositivas que significam modos de retomar os nomes próprios pela identificação profissional ou vice-versa. Em (b), temos reescrituração por definição que expande os sentidos de "isolamento"; em (c), na reescrituração por condensação "Os dois" ocorre a totalização que determina as partes totalizadas "Mandetta e Bolsonaro"; em d) ocorre por condensação o diálogo entre Mandetta e Bolsonaro. Todos esses procedimentos de retomadas de palavras e/ou expressões pelos modos de reescrituração atribuem outros sentidos ao texto, semantizando-o.

Em [B2], as razões da discordância entre os interlocutores instalam o conflito em cada um desses lugares: o dizer de um (o locutor-Mandetta) significa no dizer do outro (o locutor-Bolsonaro), mesmo que este o negue, ao fazê-lo significar.

Passamos à análise do recorte 3.

(R3) [C1] O presidente Jair Bolsonaro voltou a reclamar do Supremo Tribunal Federal (STF) pela decisão da Corte que impediu que o delegado Alexandre Ramagem tomasse posse como diretor-geral da Polícia Federal. De acordo com o chefe do Palácio do Planalto, isso representou mais uma brutal interferência do STF no Executivo, não podemos concordar com isso. [C2] [SAIBA MAIS] Em um recado à Suprema Corte, Bolsonaro disse estar sendo consciente e complacente demais. [A] "Não quero dar soco na mesa e afrontar ninguém, [B] mas peço que não afronte o Poder Executivo", salientou Bolsonaro nesta segunda-feira (15/6), em entrevista à Band News. [C3] Não queremos medir força com ninguém. Nós queremos administrar e conduzir o Brasil a um porto seguro, afinal de contas, tem muitas incertezas no ar, acrescentou ${ }^{8}$. (Grifo nosso).

O texto desse recorte é integrado de enunciados que remetem a enunciações de acontecimentos anteriores ou de outros textos, cuja relação de integração produz sentidos por ser constituída por uma relação de enunciação, visto que "enunciar num acontecimento é dizer algo com sentido, que se produz pela temporalidade própria de cada acontecimento." (GUIMARÃES, 2018, p. 41). O R3 expõe mais uma reclamação do presidente da República ao STF, construída enunciativamente pela reclamação do presidente à decisão do STF que resultou no impedimento da posse de um delegado da Polícia Federal.

A partir do agenciamento de falantes divididos politicamente, temos um Locutor (L) que relata algo dito ao Locutário (Lt). Nas relações entre o lugar que enuncia e o lugar para quem enuncia, na cena enunciativa do recorte 3 , temos um alocutário-x (o lugar que enuncia)

\footnotetext{
${ }^{8}$ Disponível em:

https://www.correiobraziliense.com.br/app/noticia/politica/2020/06/15/interna_politica,863986/bolsonaro-ao-stfestou-sendo-complacente-mas-peco-que-nao-afronte.shtml. Acesso em: jul. 2020.
} 
que desse lugar social sustenta algo (a reclamação do presidente à decisão da instituição STF) do que se enuncia pelo agenciamento do seu lugar na cena enunciativa, como aquele que relaciona um argumento e uma conclusão. Nessa linha, a argumentação não estabelece uma relação veritatitva ou convencional, ao contrário, a argumentação é "uma relação do lugar social de alocutor sobre o que se diz para um alocutário que se constitui na cena enunciativa." (GUIMARÃES, 2018, p. 106).

Vejamos a representação da relação argumentativa dos enunciados:

Argumento A - "Não quero dar soco na mesa e afrontar ninguém". [Reclamação da decisão do STF].

Argumento B - “mas peço que não afronte o Poder Executivo, salientou Bolsonaro".

Conclusão: advertência do presidente à instituição STF.

É interessante observar que o dizer do presidente, pelo lugar social que é agenciado, reveste-se de traços de autoritarismo, buscando intimidar não só o STF como qualquer instituição que se interponha em seu caminho e/ou contrarie suas 'ordens', cuja relação política é construída pela "contradição que instala este conflito no centro do dizer. E se constitui pela contradição entre a normatividade das instituições sociais que organizam desigualmente o real e a afirmação de pertencimento dos que não incluídos" (GUIMARÃES, 2017 , p. 23).

Passamos a analisar a ocorrência que se segue.

[C1] O presidente Jair Bolsonaro voltou a reclamar do Supremo Tribunal Federal (STF) pela decisão da Corte que impediu que o delegado Alexandre Ramagem tomasse posse como diretor-geral da Polícia Federal. De acordo com o chefe do Palácio do Planalto, isso representou mais uma brutal interferência do STF no Executivo, não podemos concordar com isso. ${ }^{9}$ (Grifo nosso).

Nessa ocorrência, o argumento "não podemos concordar com isso" sustenta uma posição sobre algo que a enunciação significa pelas reclamações do presidente atribuídas ao Supremo Tribunal Federal (STF). Trata-se de um argumento que discorda da interferência do STF no Executivo presente no relato do chefe do Palácio do Planalto, pelo seu lugar social de alocutário- $x$ num acontecimento de linguagem anterior ao que está sendo dito na ocorrência em [C1]. O advérbio "não" em "não podemos concordar com isso" articula-se à afirmação anterior, refutando a intervenção do STF no Executivo, ou seja, "a relação que se estabelece

\footnotetext{
${ }^{9}$ Disponível em:

https://www.correiobraziliense.com.br/app/noticia/politica/2020/06/15/interna_politica,863986/bolsonaro-ao-stfestou-sendo-complacente-mas-peco-que-nao-afronte.shtml. Acesso em: jul. 2020.
} 
entre a marca de negação e o acontecimento negado funciona como efeito do acontecimento afirmado pela negação" (FEDATTO, 2018, p. 38).

$\mathrm{Na}$ ocorrência em [C1], a sustentação da relação de argumentação se faz a partir do lugar social do Correio Brasiliense agenciado no acontecimento do R3 a dizer, visto que a argumentação "se dá como o engajamento de um lugar que enuncia uma relação entre $X$ e $Y$ enquanto uma razão $(X)$ para a conclusão (Y)” (GUIMARÃES, 2018, p. 97).

É interessante observar que a reclamação do presidente não é dirigida ao ministro que exarou o parecer impedindo a posse do delegado da Polícia Federal, mas à instituição STF, de modo a responsabilizar todos os ministros, inclusive o que emitiu a suspensão da posse. Cada um desses lugares em conflito significa que o dizer do alocutário-STF significa no dizer do locutor-Bolsonaro, ainda que este não concorde, ao fazê-lo significar.

Ainda na ocorrência em [C1], observamos que o alocutor-Correio Braziliense alude dois enunciadores: um, que assume o lugar de dizer individual, e o outro, o lugar de enunciador coletivo; o primeiro reclama da interferência do STF no Executivo e o segundo refuta essa interferência.

A expressão "voltou a reclamar" significa a repetição no dizer do presidente e funciona como uma prática institucional que retorna ao seu dizer nas relações de confronto que ele estabelece com determinadas instituições brasileiras.

Em relação aos procedimentos de reescrituração temos: em "isso representou mais uma brutal interferência do STF no Executivo, e não podemos concordar com isso", temos uma articulação por coordenação que liga uma afirmação a um enunciado negativo.

No processo de reescrituração, no enunciado acima, ocorre a reescrituração por repetição de "isso" por "isso"; e a reescritura por condensação de "isso" por "O presidente Jair Bolsonaro voltou a reclamar do Supremo Tribunal Federal (STF) pela decisão da Corte [...]". Nessa sequência temos, ainda, reescritura por aposição de nomes próprios "presidente Jair Bolsonaro" e "delegado Alexandre Ramagem” pelo processo de simetria, e a reescritura por sinonímia de "Corte" por "STF". Esses procedimentos fazem com que as palavras tornem a se significar, semantizando o texto (C1) em que aparecem.

Vejamos agora a ocorrência em [C2].

[C2] [SAIBA MAIS] Em um recado à Suprema Corte, Bolsonaro disse estar sendo consciente e complacente demais. "Não quero dar soco na mesa e afrontar ninguém, mas peço que não afronte o Poder Executivo", salientou Bolsonaro nesta segunda-feira (15/6), em entrevista à Band News.

Chama a atenção o funcionamento da expressão "SAIBA MAIS" marcada por colchetes na introdução em [C2]. Podemos dizer que essa expressão é externa à ocorrência do 


\section{ZATTAR, Neuza.}

texto e significa o acréscimo do já dito pelo presidente "em entrevista à Band News" sobre as reclamações que faz do $\mathrm{STF}$, e que retornam à enunciação da matéria publicada pelo Correio Braziliense.

Passamos à análise dos argumentos em [C2]:

[C2] "[SAIBA MAIS] Em um recado à Suprema Corte, Bolsonaro disse estar sendo consciente e complacente demais. [A] "Não quero dar soco na mesa e afrontar ninguém, [B] mas peço que não afronte o Poder Executivo."

Nessa ocorrência, o sentido da enunciação em [B] se contrapõe ao sentido da enunciação em $[\mathbf{A}]$, de modo a sobrepor o sentido de $[\mathbf{B}]$ ao sentido de $[\mathbf{A}]$, estabelecendo a articulação A mas $\mathrm{B}=\mathrm{B}$.

A presença da negação introduzindo o enunciado em [A] nos remete à relação MasSN, isto é, "o que vem introduzido pelo Mas $S N$ é apresentado como o que o locutor apresenta como comentário, no interior do que ele próprio diz, que se opõe, pelo tema, ao que se teria dito, ou se disse, na enunciação de um interlocutor suposto ou real" (GUIMARÃES, 2002, p. $85)$.

Como procedimento de sentidos, a articulação em "Não quero dar soco na mesa $\mathbf{e}$ afrontar ninguém", pela presença da conjunção "e", temos a articulação por coordenação que "emprega elementos de mesma natureza e os organiza como se fossem um só da mesma natureza de cada um dos constituintes" (GUIMARÃES, 2018, p. 81). E em "estar sendo consciente e complacente demais" temos um exemplo de predicação muito particular em que os atributos são auto-atribuídos pelo próprio alocutor.

Passamos agora à última ocorrência em [C3].

[C3] Não queremos medir força com ninguém. Nós queremos administrar e conduzir o Brasil a um porto seguro, afinal de contas, tem muitas incertezas no ar, acrescentou.

O enunciado "Não queremos medir forças com ninguém" liga-se ao [C2], e busca justificar o que foi dito na enunciação anterior, mantendo o conflito com o STF, para, em seguida, advertir: "afinal de contas, tem muitas incertezas no ar."

Nessa ocorrência, o Locutor alude o lugar de dizer do enunciador coletivo, que enuncia do lugar de chefe supremo das forças armadas, às quais o Governo pode recorrer. Aqui, o enunciador, ao representar o dizer do Locutor, sustenta o que está significando para si.

O dizer nessa ocorrência, ao mesmo tempo intimidatório e ambíguo, deixa em suspenso o que quis dizer com "muitas incertezas no ar", enunciado que é sustentado pelos argumentos "Não queremos medir força [...]" e "Nós queremos administrar [...]".

Vejamos a relação argumentativa pela paráfrase da ocorrência em [C3]. 
[C3’] (A) Não queremos medir força com ninguém. Nós queremos administrar e conduzir o Brasil a um porto seguro, (B) porque tem muitas incertezas no ar, acrescentou.

Nessa paráfrase, a relação argumentativa se dá pela relação [X PT Y], em que [Y] funciona como conclusão para o argumento em [X], produzindo relação de sentidos ao texto. Segundo Guimarães (2018), o modo como a articulação [A porque $B$ ] estabelece sua integração ao texto se faz pelo modo como se articulam os enunciados. E são estas relações que "produzem uma orientação do sentido das relações entre enunciados no texto que são próprias do funcionamento enunciativo destes enunciados em virtude de suas articulações" (GUIMARÃES, 2018, p. 111). A essa orientação de sentido, Guimarães (2018) chama de argumentatividade.

Para compreender a relação entre esses articuladores, apresentamos o conceito de argumentação orientativa que, conforme Guimarães (2013, p. 276), "é a apresentação pelo locutor ao seu alocutário de uma relação de sentidos que orienta a direção do dizer como direção necessária." E uma vez que a argumentação orientativa se dá na cena enunciativa, temos que considerar os lugares sociais de quem diz e para quem diz, por entender que a argumentatividade é marcada pela relação L - AL na cena enunciativa em que são agenciados.

Desse modo, a orientação de sentido em (B) "porque tem muitas incertezas no ar, acrescentou" é uma articulação do tipo argumentatividade diretiva por estabelecer uma direção do dizer, orientando-o diretivamente para uma conclusão. Ou seja, a enunciação introduzida por porque se contrapõe à enunciação anterior, orientando o dizer para uma direção conclusiva (única). Assim, "Não quero dar soco na mesa e afrontar ninguém" é o argumento e "porque peço que não afronte o Poder Executivo" é a conclusão, que equivale a Argumento - Conclusão.

Além da argumentatividade diretiva, temos a articulação do tipo argumentatividade concessiva representada por [XNE Y] que se lê [X NO ENTANTO Y], cuja relação equivale a Argumento - Argumento.

Empregando o articulador "no entanto" à enunciação "Não quero dar soco na mesa e afrontar ninguém, no entanto peço que não afronte o Poder Executivo", temos uma articulação do tipo argumentatividade concessiva, cuja relação significa que o dito em [B] se relaciona com o todo do texto orientando a continuidade do texto. A esse modo de apresentar a continuidade do texto como elemento de significação é chamado por Guimarães de argumentatividade da enunciação ou orientação argumentativa.

\section{Finalizando}


Observamos pelas análises empreendidas que os processos de significação da argumentação e da argumentatividade se dão em cenas enunciativas a partir da relação entre um $e u$ que diz algo a um $t u$, visto que os lugares sociais de quem diz e para quem diz são marcados pela relação $\mathrm{L}$ - AL.

Nessa linha, o sentido da argumentação e da argumentatividade é político, por se dar em espaços de enunciação que agenciam os falantes (locutor-locutário, alocutor-alocutário e enunciador) pela distribuição desigual das línguas e, por se tratar de uma relação de linguagem, de uma relação enunciativa, afasta-se da argumentação tratada como persuasão ou convencimento de alguém.

É preciso destacar a importância dos procedimentos de articulação e reescrituração na construção semântico-argumentativa dos textos analisados. A articulação trata das relações de contiguidade que sustentam linguisticamente a integração de um enunciado a um texto, e a reescrituração trata das relações de integração de um enunciado a um texto, sustentando-o semanticamente. Esses procedimentos, pela própria especificidade, ao funcionarem no texto de modo integrado, produzem sentidos ao texto.

Observamos nos recortes analisados que os sentidos da argumentação e da argumentatividade se constituem pelo confronto, discordância e advertência enunciativos, que sustentam uma posição sobre algo que a enunciação faz significar.

\section{Referências}

DUCROT, Michel; ANSCOMBRE, Jean Jacques. L'argumentation dans la langue. 2. ed. Bruxelles: Mardaga. 1983.

FEDATTO, Carolina P. Perspectivas enunciativas da negação: efeitos de sentido dos modos de dizer. In: Revista eletrônica Língua e enunciação: roteiros e estações. DIAS, Luiz Francisco. (Org.). Belo Horizonte, FALE, UFMG, 2018.

GUIMARÃES, Eduardo. Texto e argumentação: Um estudo de conjunções do português. 3. ed. Campinas, São Paulo: Pontes Editores, 2002.

. A enumeração: funcionamento enunciativo e sentido. In: Cadernos de Estudos Linguísticos. Campinas, São Paulo, 51 (1): 160, Jan./Jun. 2009. . Análise de texto - procedimentos, análises, ensino. 2. ed. São Paulo: Hucitec, 2012.

Argumentação e argumentatividade. In: Revista do Programa de Pós-Graduação em Letras da Universidade de Passo Fundo, v. 9, n. 2, pp. 271-283, jul./dez. 2013

2017.

. Semântica do acontecimento. 4. ed. Campinas, São Paulo: Pontes Editores,

. Semântica: enunciação e sentido. Campinas, São Paulo: Pontes Editores, 2018. Ministério da Educação. Redação do ENEM 2018. Cartilha do Participante. Apresentação. Brasília/DF, 2018, p. 7. 


\section{ZATTAR, Neuza.}

PERELMAN, Chaïm; OLBRECHTS-TYTECA, Lucie. Tratado da Argumentação - A nova retórica. Trad. Maria E.G.G. Pereira. São Paulo: Martins Fontes, 1996.

ZOPPI-FONTANA. Mónica. Retórica e argumentação. In: Introdução às Ciências da Linguagem: discurso e textualidade. LAGAZZI-RODRIGUES, Suzy; ORLANDI, Eni. (Org.). Campinas, São Paulo: Pontes Editores, 2006.

Recebido em: 13/02/2021; Aceito em: 04/03/2021. 